\title{
Arranjos da sobrevivência escrava na cidade de São Paulo do século XIX
}

\author{
Maria Cristina Cortez Wissenbach \\ Pós-graduanda em História Social \\ Departamento de História - USP
}

Em meados dos anos 50, em seu artigo "Do Escravo ao Cidadão", Florestan Fernandes enunciava as bases de sua teoria acerca do processo de integração ou marginalização dos negros brasileiros à sociedade de classes. Nesta ocasião, avaliando a presença do elemento negro - cativo ou forro - na cidade de São Paulo e nos processos históricos que marcaram os finais do período escravista, o autor ressaltava a situação periférica em que se encontravam tais camadas sociais (1). Localizando-as como um corpo estranho à sociedade da época, afirmava, posteriormente, que o universo negro se colocava "como se estivesse dentro dos muros da cidade, mas não participasse coletivamente de sua vida econômica, social $e$ politica" (2). Ao formular sua obra clássica, Florestan Fernandes man-

(1) - FERNANDES, Florestan. "Do escravo ao cidadão". Relações Raciais entre Brancos e Negros em São Paulo. Ensaio sociológico sobre as origens, as menifestações e os efeitos do preconceito de cor no município de São Paulo. Direção de Roger Bastide e Florestan Fernandes. São Paulo, UNESCO/Anhembi, 1955.

(2) - FERNANDES, Florestan. "A persistência do passado". O Negro no Mundo dos Brancos. São Paulo', DIFEL, 1972, p. 85. 
teve-se na mesma linha interpretativa, generalizando-a e destacando as informações provenientes do regime escravista, que produziu indivíduos incapazes de se adequar ao novo universo das relações sociais, classistas e assalariadas. Como decorrência dessas deformações, a passagem da escravidão para a liberdade deu-se de maneira traumática para o conjunto dos grupos escravos, traumatismo que se refletiu nas adaptações socialmente problemáticas dos libertos: a sua entrega ao ócio, ao alcoolismo e à criminalidade, a incapacidade de submeterem-se a novos padrões de trabalho, de competirem em termos de igualdade com os trabalhadores imigrantes e finalmente, de constituírem arranjos familiares e sociais estáveis (3).

Ao acompanhar, retroativamente, a movimentação dos negros na sociedade paulistana da segunda metade do século, as evidências das fontes primárias apontam em sentidos contrários: não só a participação dos escravos aparece mais intensa do que o anteriormente imaginado, como também revela-se uma sociedade que usufruiu, até a Abolição, senão do trabalho escravo, ao menos das formas transitórias entre a liberdade e a escravidão, produzidas pelo gradualismo emancipacionista brasileiro (4). Reconstituindo, em outro sentido, as condições de vida e de trabalho dos escravos e manumissos, e registrando seus depoimentos, as fontes judiciárias remarcam experiências sociais nas quais se faziam presentes linhas de continuidade entre uma e outra vivência (5).

Na presente comunicação pretende-se apontar algumas das maneiras pelas quais os escravos se integravam no mercado de trabalho da cidade, se adequavam à lógica das relações sociais de trabalho vigentes na época e desfrutavam de elementos dados pelo mundo urbano. No geral, a vivência citadina lhes possibilitava formar não somente uma personalidade escrava ciente de suas prerrogativas e dos limites que lhes eram impostos, como também de dilatá-los, assimilando aprendizados socialmente compatíveis com a vida em liberdade. Tais experiências, passíveis de serem

(3) - FERNANDES, Florestan. A Integração do Negro na Sociedade de Classes. $3^{\text {a }}$ edição, São Paulo, Ed. Ática, 1978. Especialmente Cap. I, item 3: "Expansão urbana e desajustamentot estrutural do negro".

(4) - Entre as fontes primárias localizadas no Arquivo do Estado de São Paulo, ver sobre o assunto a coleção "Ofícios Diversos da Cidade de São Paulo" e os autos do Juizado de órfãos e Ausentes, da segunda metade do século XIG.

(5) - Autos Crimes de São Paulo, Anos: 1850 a 1879, AESP. A importância da análise "dos rituais de passagem entre a desagregação da escravidão e o trabalho livre" foi sugerida pelo artigo: "Nas fímbrias da escravidão urbana: negras de tabuleiro e de ganho", da professora Maria Odila Leite da Silva Dias. Estudos Econômicos, IPE/USP, 15, 89-109, 1985. 
observadas através dos autos criminais, alteravam as regras subservientes da escravidão, provendo-as de novos conteúdos, e transformavam as relações entre senhores e escravos num jogo contínuo de direitos e deveres.

O ponto de partida para a análise dos comportamentos escravos na cidade de São Paulo é avaliar a natureza transitória das relações sociais de trabalho vigentes na segunda metade do oitocentos e a relatividade de seus aspectos modernos. O contingente escravo na cidade era reduzido: ao longo do século XIX, nunca ultrapassou a casa dos $30 \%$ da população paulistana, diminuindo progressivamente a partir de 1850 em função da inflação dos preços de escravos e das demandas das áreas produtivas cafeeiras - e reduzindo-śe a um número pouco expressivo às vésperas da Abolição (6). Assim, se as relações de trabalho eram predominantemente livres, envolviam poucas inovações quando comparadas ao trabalho escravo (7). Pressupondo fortes laços pessoais entre empregadores e empregados, as formas de coerção e disciplina de trat balho encontravam-se distantes das regras de exploração assalariada. O mercado de trabalho na cidade, nessa época, mostrava-se, consequentemente, bastante heterogêneo e o escravo não era, nele, um elemento dissonante.

Até meados dos anos 70 , a pobreza orgânica da sociedade paulistana, os ritmos intermitentes de sua urbanização, o lento desenvolvimento da economia no sentido da especialização urbana e as demandas do setor

(6) - Dados sobre a população do termo de São Paulo: MƯLLER, Daniel Pedro. Ensaio D'un Quadro Estatístico da Província de São Paulo. Ordenado pelas leis provinciais de 11 de abril de 1836 e 10 de março de 1837. 3a edição facsimilada, São Paulo, Governo do Estado de São Paulo, 1978; "População da Província de São Paulo - 1854. Estatística organizada por Machado de Oliveira, anexo ao discurso com que o vice-presidente da Província abriu a Assembléia Legislativa no dia 18 de fevereiro de 1856". Relatórios dos Presidentes da Província de São Paulo. Soã Paulo, Typografia Dous de Dezembro, 1856. Dados dos censos nacionais de 1872 e 1886: apud FERNANDES, Florestan. "Do Escravo ao Cidadão", op. cit. pp. $36: 45$.

(7) - Sobre o assunto, analisando as condições de trabalho nas indústrias têxteis do século XIX, afirmou Stein: "As relações de trabalho nas primeiras fábricas exigiam, sem dúvida, pouca inovação, pois os empresários acreditavam, de modo geral, que os trabalhadores eram dóceis, ignorantes e carentes de orientação. Para lidarem com essa força de trabalho, adotaram uma política que não diferia muito daqueles dos benevolentes patriarcas das grandes propriedades rurais. Durante meio século (1840-1890) o recrutamento e treinamento da força de trabalho nas fábricas têxteis teve como matriz uma sociedade escravagista .... No século XIX, os proprietários das fábricas tratavam seus operários diaristas da mesma forma que os fazendeiros de café ou os senhores de engenho tratavam seus escravos ou os poucos trabalhadores livres que recebiam pagamento por dia de trabalho". STEIN, Stanley. Origens e Evolução da Indústria Têxtil no Brasil. Rio de Janeiro, Ed. Campus, 1979 , p. 63. 
público ligado à infra-estrutura da cidade traduziam-se na composição de uma mão-de-obra híbrida, formada tanto por figuras proto-assalariadas, quanto por escravos em suas diversas modalidade e ainda por tipos juridicamente intermediários entre a escravidão e a liberdade (8). Ao lado dos escravos coexistiam, dessa forma, diaristas, órfãos tutelados, colonos imigrantes presos por contratos, agregados, africanos livres, libertos condicionais, ingênuos, libertos da guerra do Paraguai, etc.

Na São Paulo da época os escravos encontravam-se congregados a um setor maior da sociedade citadina, interseccionados a grupos sociais heterogêneos, que compunham, grosso modo, os despossuídos, os dominados, aqueles que se mostravam alijados do poder político e econômico. Sob múltiplos aspectos os escravos aparentavam-se com os libertos e am. bos aproximavam-se dos brancos pobres. Sem neutralizar condiçóes sócio-jurídicas diferenciadas, revelavam-se elementos de aderência e continuidade entre eles: compartilhavam as mesmas funções, movimentavam-se física e socialmente de maneira similar e, aos olhos do poder público, confundiam-se enquanto agentes de desordem social (9). Vistas, no entanto, sob um prisma particular, as vivências escravas mostravam-se singulares, pois inseriam-se em conflitos e enfrentamentos sociais específicos, produzidos a partir das ambigüidades entre os níveis de autonomia permitidos e os elementos inerentes à escravidão.

Dentro da hierarquia ocupacional dos escravos urbanos sobressaíam inicialmente os de ganho. $\mathrm{O}$ sistema de ganho, prática comum e característica de diversas cidades brasileiras, desde os tempos coloniais, expressava a maleabilidade da instituição escravista e sua capacidade em seadequar a contextos economicamente distintos e a situações senhoriais diversas. Na cidade de São Paulo, onde prevalecia a pequena e média posse de escravos e demandas economicamente diversificadas, era essa a forma pela qual os senhores, em sua maioria, exploravam o trabalho escravo e usufruiam das rendas por ele geradas (10). No contexto econômico da segunda metade do século, tal sistema adquiria um renovado conteúdo, pois, ao mesmo tempo em que compatibilizava os escravos ao

(8) - DIAS, Maria Odila Leite da Silva. Quotidiano e Poder em São Paulo no Século XIX. São Paulo, Ed. Brasiliense, 1984.

(9) - IDEM, especialmente capítulo "Padeiras e quitandeiras da vila: a resistência contra o fisco"; SOUZA, Laura de Mello e. Desclassificados do Ouro. A pobreza mineira no século XVII. Rio de Janeiro, Edições Graal, 1982, especialmente capítulo: "Da utilidade dos vadios"; FIGUEIREDO, Luciano R. de A; \& MAGALDI, Ana Maria B. de M. "Quitandas e Quitudes. Um estudo sobre rebeldia e transgresso femininas numa sociedade colonial". Cadernos de Pesquisa, Fundação Carlos Chagas, 54, 1985.

(10) - DIAS, Maria Odila Leite da Silva. Op. cit. pp. 83: 106. 
contexto do trabalho remunerado, resguardava o sentido maior da propriedade escrava (11).

Os múltiplos significados dessa modalidade de emprego da mão-de-obra cativa têm sido destacados pelos estudiosos da escravidão nas cidades. Seu funcionamento, amplamente conhecido, manteve-se inalterado nos diversos centros urbanos brasileiros (12). No geral, a prática do ganho associava-se a escravos especializados ou semi-qualificados: pedreiros, carpinteiros, carregadores, sapateiros e alfaiates que agenciavam, comumente por conta própria, seus serviços a terceiros e recebiam jornais destinados em sua grande parte aos senhores. Através do ganho as funções escravas eram desempenhadas fora do âmbito da tutela direta dos senhores, exigindo, deste tipo de trabalhadores, iniciativa, destreza e habilidade profissional. Além disso, era costume reconhecido pela maioria dos senhores que uma parte da remuneração caberia aos próprios cativos. A independência no trabalho e o reconhecimento de ganhos próprios tinham, no entanto, um contraponto: era ustual também, sobretudo nas situações de senhores remediados, que tais escravos garantissem parte ou seu total sustento, devendo produzir recursos próprios para o comer, o vestir e, muitas vezes, para o morar (13).

Os processos criminais em que estiveram indiciados escravos ganhadores testemunham, ao registrarem vivências concretas, acima de tudo, as dificuldades que eles encontravam para cumprir o duplo encargo que lhes era atribuído: a auto-stubsistência e os deveres para com os senhores. Exemplo das exigências redobradas que recaiam sobre tais escravos pode ser encontrado no processo criminal que envolveu, em 1863, o casal formado por José Mina, africano de 53 anos aproximadamente, oficial de

(11) — GRAHAM, Richard. "Escravidão e desenvolvimento econômico. Brasil e Sul dos Estados Unidos". Estudos Econômicos, vol. 13, 1, IPE/USP, 1983; FREITAS, Décio. Inssurreições Escravas. Porto Alegre, Editora Movimneto, 1976, p. 17.

(12) - Entre outros: MATTOSO, Kátia de Queirós. Ser Escravo no Brasil. São Paulo, Editora Brasiliense, 1982; KARASCH, Mary. Slave Life in Rio de Janeiro 1808-1850. Princeton University Press, 1982; RË́lS, João José. Rebelião Escrava no Brasil. A História do Levante dos Malês (1835). São Paulo, Ed. Brasiliense, 1986; ALGRANTI, Leila Mezan. O Feitor Ausente. Estudo sobre a escravidão urbana no Rio de Janeiro - 1808/1821. Dissertaçấo de mestrado apresentada ao Departamento de História da USP. São Paulo, 1982.

(13) - Maria Odila da Silva Dias sugere que, na São Paulo da segunda metade do século, frente à carestia e inflação dos gêneros alimentícios e dos aluguéis de casas, e ao processo de empobrecimento dos pequenos proprietários de escravos tais práticas teriam se acentuado, aumentando a frequência de escravos ganhadores que supriam sua própria sobrevivência. Op. cit. pp. 99: 105. 
pedreiro, e sua mulher, de serviços domésticos (14). Morando sós, na rua da Santa Casa, empenhavam-se para satisfazer ao senhor a quantia de dois mil e oitocentos réis de jornal, mantendo, dessa forma, a anuência de uma relativa independência. Para isso, a principal fonte de renda era os serviços realizados pelo escravo como pedreiro, pelos quais ganhava, em média, dois mil réis por dia. A complementação necessária provinha de recursos que eram por eles improvisados: a mulher servia, em sua casa, refeições a outros escravos ou a libertos; o marido vivia aplicando golpes nos seus semelhantes, e reclamava, junto ao juízo de Paz do Distrito do Norte da Freguesia da Sé, os jornais não pagos (15). Apesar das dificuldades, os efeitos da autonomia se faziam sentir no comportamento do escravo: não só agia como também se dizia homem livre, usando do nome de seu senhor somente quando necessitava de um patrono e processava seus empregadores, maus pagadores, como um indivíduo juridicamente livre, assessorado por estudantes da Academia de Direito.

Relações tensas de sobrevivência, que aproximavam drasticamente os escravos de ganho a meios ilícitos, foram freqüentes entre processos que relatam condições devida mantidas nos limites do mínimo vital. Ao ser inquerido pelas autoridades judiciárias por um crime de roubo, afirmava, em 1864, Tomás, escravo de Carneiro Leão: "que elle interrogado nunca practicou facto de igual natureza, mas que urgido pela necessidade, por quanto achava-se sem camiza, subtraiu" (16). Continuando seu interrogatório, completava "que teve necessidade desta camiza como também tem tido em outras ocasiões pois que seu senhor não the dá roupa sendo certo que aquella que veste elle interrogado é comprada a expensas suas".

De forma similar, diante da intermitência de serviços oferecidos no mercado citadino, ser requisitado para consertar o telhado de uma casa significava para José Preto, escravo do Alferes Manoel de Campos Penteado, a possibilidade de almoçar (17). Em 1870, perguntado em juízo sobre as ameaças que fizera aos estudantes moradores na rua do Quartel, respondeu que naquela ocasião "não estava certo do juízo porque não

(14) - P. 881 de 1863. Todos os autos judiciários criminais referidos encontram-se no Arquivo do Estado de São Paulo (AESP), nas caixas intituladas "Autos Crimes de São Paulo", compreendidas entre os anos de 1850 a 1880 .

(15) - Neste caso, o escravo foi acusado de crime de estelionato contra Domingos Jordão, liberto. Investigando a utilização de recursos fraudulentos, no caso passar como homem livre, as autoridades judiciárias anexaram cópia de um ato, datado de 1862, do Juízo de Paz do Distrito do Norte da Freguesia a Sé, no qual o réu José Mina ligitimava contra o português José da Rosa Machado, por valores indevidamente pagos.

(16) - P. 1061 de 1864 .

(17) - P. 1565 de 1870. 
tinha almocado neste dia e sendo chamado para o dito conserto ficou, satisfeito de ir ganhar esse dinheiro". Mas, irritado pela fome e pelos debiques dos estudantes, o escravo acaba por ameaçá-los com uma faca que portava na cintura. A origem da desavença entre eles é reveladora: no momento em que the foi perguntado se era livre ou escravo respondeu, textualmente: "eu sou senhor de si", provocando uma explosão de gargalhadas entre os estudantes.

A situação de sobrevivência era mais tranqüila entre os ganhadores que usufruíam do sustento senhorial, ou seja, quando ao mesmo tempo em que se beneficiavam da autonomia no trabalho, tinham suas necessidades básicas asseguradas. Porém, mesmo nessas circunstâncias, talvez ideais, estavam sujeitos a outras contingências. Exemplo característico foi a vivência, descrita em processo criminal, de Pedro, de nação CongoAngola, de 25 anos e escravo do Cônego Fidélis José de Moraes, o qual foi acusado, em 1858, de planejar o homicídio de seu senhor (18). Casado com Josepha, escrava do mesmo cônego e com dois filhos, ao longo de sua permanência em São Paulo havia acumulado uma quantia significativa de dinheiro através de seu trabalho em inúmeras obras da cidade. Mas, se de um lado, o sustento senhorial the permitia acumular, de outro surgia a necessidade de proteger sua propriedade monetária das investidas senhoriais. Para tanto, mantinha o dinheiro guardado ora junto à amante, a escrava Joana, ora sob os cuidados do pedreiro alemão, Henrique Abler, seu parceiro em diversos serviços. Tais artimanhas não impediram, no entanto, que a quantia de um conto de réis fosse descoberta pela senhora da escrava Joana, que dela se apropriou sob a suspeita de furto.

Uma vez destituído do pecúlio arduamente acumulado, Pedro procurou, inicialmente, Luiz Gama, advogado negro sensível às causas dos escravos. Segundo o depoimento deste último, como testemunha, "havião quatro meses mais ou menos em huma manhã o réo presente procurou a elle informante em huma casa na rua da Constituição para aconselhar-se sobre o seguinte facto: que tendo elle réo relações illicitas com uma escrava do Capitão Osório, deo a esta preta certa quantia avultada, que não foi declarada, para realização de sua liberdade; que a referida preta guardiou este dinheiro em huma caixa e chegando a notícia da existência deste dinheiro ao conhecimento da senhora da dita preta, mandou a dita senhora castigal-a e apoderou-se do dinheiro allegando ter sido roubado a que o réo protestou ser falso". Dizia-lhe ainda o escravo que, na oca-

(18) - P. 353 de 1858 . 
sião, "tinha diifculdade de procurar um advogado profissional", ao que the respondeu Luiz Gama que "isto era difícil pois seu senhor não consentiria". Dessa forma, invalidadas as tentativas do escravo em reaver o dinheiro por vias legais, a solução limiar planejada seria o homicídio do senhor, logo após este ter assinado a carta de alforria reclamada.

Assim, embora prática costumeira entre as concessões senhoriais, as posses dos cativos, até a promulgação da Lei do Ventre Livre, em 1871, não estavam legalmente protegidas, sendo-lhes vedado qualquer iniciativa jurídica, no sentido de reclamar aquilo que era seu (19). Por outro lado, mesmo quando reconhecida, existia uma aura de desconfianças que cercava os escravos que se apresentassem "em público com quantias superiores à sua condição". Na noite de 17 de outubro de 1853 foi preso pela patrulha da cidade, no largo do Chafariz da Misericórdia, o escravo Mariano de Dona Fortunata Lopes, por estar em brigas com uma parceira e por trazer a quantia de 7 mil réis em cobres, dentro de seu saco de jornal (20).

Desejar formar um pecúlio para a compra da liberdade era igualmente indício de eventuais indisciplinas. Em 1868, perguntado pelas autoridades judiciárias se suspeitava da participação de suas domésticas no roubo efetuado em sua residência, afirmava Fidélis Cigmaringa de Moraes que não, "pois que entre eles sempre houve respeito, recordando-se apenas que sua escrava a pouco tempo havia-lhe dito que tinha desejos de liberdade $e$ de ajuntar dinheiro" (21). Ao mesmo tempo em que as práticas de exploração da mão-de-obra autorizavam o trabalho remunerado e destinavam parte dos ganhos aos próprios cativos, a posse de dinheiro e os desejos de formação de pecúlios eram estranhamente percebidos pela camada dominante e pelos poderes públicos.

Dificuldades de sobrevivência, desconfianças sociais, percalços a que estavam sujeitos os bens e ganhos cativos eram, portanto, efeitos negativos associados ao trabalho urbano, que, no entanto, se somavam à uma série de novos aprendizados. $\mathrm{O}$ acesso ao dinheiro, uma certa esperteza em contornar as adversidades e a mensuração do trabalho em valores mo-

(19) - A partir de 1871, com as disposições da Lei do Ventre Livre, os pecúlios escravos eram juridicamente reconhecidos: os escravos poderiam depositálos em juízo, sob a custódia do Juizado de órfãos, quando da existência de litígios com seus senhores, ou, quando da anuência senhorial, na Caixa Econômica.

(20) - P. 312 de 1853

(21) - P. 1492 de 1868 a 1872. 
netários contribuíam para forjar nos escravos a consciência do valor que tinham, tornando, por vezes, mais transparente a exploração senhorial.

Enquanto que o escravo Pedro, em 1858, listava de memória os diversos serviços, os nomes dos proprietários das obras nas quais trabathara e detalhava os valores recebidos em cada uma delas (22), Carlos, africano pertencente a Jacob Asser, dez anos após, refazia sua trajetória como escravo e expressava a clara percepção dos interesses senhoriais implícitos na exploração de seu trabalho (23). Tido e reconhecido como escravo insubordinado, em juízo dizia que "a razão pela qual elle eccusado fora remetido para o serviço público na estracla de ferro fora de seus salarios serem recolhidos ao cofre e distribuidos pelos herdeiros", para que, dessa forma, "auferissem lucros do prestimoso serviço delle accusado que trabalhava dia e noite..." Tais percepções, acrescidas daquelas provenientes da existência de famílias organizadas, da necessidade de agenciar seus trabalhos, e do viver autônomo, alteravam as maneiras pelas quais os escravos se colocavam diante de seus senhores, de seus parceiros e dos demais grupos da sociedade da época.

As relações escravistas, que emergiam a partir dessas formas de utilização do trabalho escravo, desenvolviam-se em sentidos distintos daquelas paternalistas, que caracterizavam o mundo da casa grande e da senzala, ou das envolvidas na extrema disciplina e ritmo de trabalho das grandes propriedades escravistas. Em grande parte das relaçôes na cidade interpunha-se, entre escravos e senhores ,a mediação monetária. A fidelidade e submissão dos escravos eram avaliadas a partir da pontualidade e honestidade no acerto de contas com o senhor, ao final de um trabalho, de uma semana ou de um mês.

Nos depoimentos escravos recolhidos pelos processos criminais aparece patente esta configuração: explicando o fato de nunca ter sido maltratado pelo senhor, afirmava um escravo "por nunca lhe ter dado des. gosto, sendo seu senhor muito bom e sendo elle interrogado muito pontual nas contas com o senhor" (24). Esta concepção, que limitava a submissão a um estrito cumprimento de contas, autorizava, em contrapartida, posturas independentes e voluntariosas. Segundo uma testemunha, o mesmo escravo "vivia armado ora com uma ora com outra arma; que quando seo senhor the mandava fazer alguma coisa nada fazia e sahia para a rua, se the dizia que viesse às Aves-Marias vinha as oito e nove horas da

(22) - P. 353 de 1858.

(23) - P. 1507 de 1868.

(24) - P. 353 de 1858. 
noite, se a mulher na cuzinha lhe dizia alguma coisa ficava bravo, sempre promettendo metter a faca e dar pancadas em quem se importasse com com sua vida..." (25).

Em suma, como seqüelas da intromissão do dinheiro nos compromissos entre senhores e escravos, do desempenho autônomo e da liberdade de movimento, o trabalho citadino pressupunha mudanças profundas nas práticas disciplinares. Invalidava a violência como recurso de submissão, colocando, em seu lugar, mecanismos mais producentes, como a promessa da alforria e a liberdade condicional (26). No mesmo sentido, a autorização de espaços sociais próprios, de estruturas familiares e de certos direitos eram igualmente necessários para a manutenção da estabilidade das relações entre senhores e escravos. Vistos sob essa ótica, os elementos conformadores da organização social escrava apresentavam-se orgânicos ao próprio funcionamento da escravidão nas cidades, resultando menos de atitudes complacentes dos senhores de escrayos.

Com isso não se pretende afirmar que tais relações fossem destituídas de conflitos. Pelo contrário, nos processos criminais surgem situações de enfrentamento provenientes do desrespeito aos direitos vistos pelos escravos como justos. E o caso, por exemplo ,de Joaquim, africano carreiro, de 50 anos aproximadamente, que assassinou, em 1861, sua senhora, Dona Jesuína Maria de Godoy (27). Ao explicar o seu ato, nota-se o avolumar de tensões em que estiveram imersas suas relações com o mando senhorial: a destruição de sua família pelas vendas sucessivas de sua mulher e filhos, os castigos frequientemente aplicados em sua enteada e, finalmente, sua obrigação de trabalhar dia e noite, sem descanso. O epi-

(25) - P. 353 de 1858 .

(26) - A questão da promessa da alforria enquanto recurso disciplinar tem sido destacada por diversos trabalhos, entre eles, os mencionados na nota 11, acrescentando-se o artigo de Manuela Carneiro da Cunha: "Sobre os silêncios da lei. Lei constumeira e positiva nas alforrias de escravos no século XIX". Cadernos, IFCH/UNICAMP, 4, 1985. Particularmente em São Paulo, a transformação dos escravos em libertos condicionais, a partir de 1871, demonstrou ser recurso senhorial para salvaguardar a propriedade escrava dos ataques legais dos abolicionistas. A confluência de interesses senhoriais, ativismo abolicionista e iniciativas escravas nas soluções gradualistas pôde ser verficada entre os recursos de ações de liberdade que tramitaram pelo Tribunal da Relação de São Paulo. Cf. Coleção Documentos Históricos - Tribunal da Relação, Arquivo do Poder Judiciário do Estado de São Paulo. Sobre as múltiplas inferências do gradualismo emancipacionista na desagregação do regime escravista, ver o estudo desenvolvido por Rebecca Scott sobre Cuba: "Abolição gradual e a dinâmica da emancipação dos escravos em Cuba, 1868-86..' Estudos Econômicos, IPE/USP, vol. 17, 3, setembro/dezembro 1987 .

(27) - P. 1090 de 1861. 
sódio que precedeu o homicídio ilustra o ponto de saturação das relações entre o escravo e sua senhora: no dizer de uma testemunha ocular: "o acuzado pouco antes do assassinato mostrou-se zangado $e$ atrevido por Dona Jesuina ter declarado que elle escravo poderia presindir da carroca para conduzir um colchao a cidade, ao que o acusado the respondera que não era burro de carga".

Aliados a este, outros depoimentos explicitam que os escravos não suportavam ser tratados de maneira reificada e exprimiam, através de seus atos, a aversão em serem negociados como se fossem animais ou objetos, ou serem vendidos a senhores que não fossem de sua própria escolha. Demonstravam, assim, de forma enviesada, o repúdio ao princípio básico da escravidão: o fato de que, acima de tudo, eram propriedade alienável de seus senhores.

Até aqui limitei-me a narrar situações circunscritas às experiências dos ganhadores, por acreditar serem estes a expressão mais acabada do trabalho escravo nas cidades. Porém, da mesma forma que neles, é possível visualizar nos demais escravos citadinos, e mesmo entre os dos arredores rurais de São Paulo, traços semelhantes. A remuneração direta ou residual do trabalho e a liberdade de movimento não eram exclusivas aos escravos especializados; delas participavam também tropeiros, carreiros, vendedores ambulantes que, ao trabalharem nas ruas, nos mercados e nos campos ao redor da cidade, auferiam ganhos extras de seus senhores. Era comum, por exemplo, o pagamento aos tropeiros e carreiros, no geral na forma de gêneros - animais ou produtos - que seriam por eles vendidos para a obtenção de jornais. Em outras ocasiões, os senhores concediam pequenos incentivos a seus trabalhadores escravos: a licença de usar o carro para vender capim na cidade; de dispor de roças de cultivo, cujos gêneros seriam comercializados nos mercados locais. A outros escravos, sobretudo aos domésticos, autorizavam-se também tarefas autônomas, realizadas nos intervalos dos afazeres diários: vender quitandas, doces e frutas, nas ruas; vender capim ou lenha; pedir esmolas. De tais atividades, vistas como interesses residuais concedidos pelos amos, os cativos retirariam os parcos vinténs de sua sobrevivência.

Assim, direta ou indiretamente, em maior ou menor escala, os escravos lidavam com capitais líquidos e através deles integravam-se, como consumidores e produtores, ao mercado e às exigências da sociedade (28). A historiografia tem limitado as práticas de remuneração ao sistema de

(28) - A importância da economia residual dos escravos na conformação de espaços autônomos no contexto das plantations - e, consequentemente, na passagem à liberdade - foi sublinhada por: MINTZ, Sidney. Caribbean Transformations. 
ganho, associando este, por sua vez, a uma maior possibilidade de obtenção da alforria. Porém, as interpretações correntes minimizam, até certo ponto, o fato de que entre os ganhos reduzidos e a compra da liberdade interpunha-se uma série de outras contingências e necessidades. Necessidades impostas pelo circuito monetário da cidade, cotidianas e preementes ao processo da auto-afirmação cativa. Poder alugar um quarto, para deixar suas ferramentas, objetos, móveis e roupas ;fazer mimos e presentes a suas parceiras; gastar com fumo e aguardente nos armazéns da cidade; comer, ter suas roupas lavadas, etc., significava, muitas vezes, o reconhecimento de suas individualidades nos relacionamentos sociais, sendo por isso, talvez, tão importante quanto a alforria.

O que se pretende sugerir, de outra parte, é que a alforria se colocava, para a maioria dos escravos, enquanto objetivo distante, difícil de ser atingida (29). Em 1867, acalentando sonhos de liberdade que se realizariam em plenitude em sua terra natal, a África, Theodora, escrava doméstica do Cônego Sigmaringa de Moraeś, obtinha minúsculos rendimentos vendendo aos soldados por três vinténs e pedindo esmolas nas missas de domingo (30). Vinda da zona rural paulista, em quatro anos de vida na cidade havia conseguido acumular 129 mil réis, numa época em que preço de uma mulher escrava girava em torno de 1 conto de réis. Distanciando-se cada vez mais de setı sonho, a escrava passava a se utilizar de outras estratégias: algumas elaboradas a partir de sua própria vivência, como africana e como mulher casada, outras apreendidas no convívio urbano. Incapaz de formar o pecúlio por si só, concebia a reconstituição de sua família como projeto de acumulação e pedia ao senhor, incessantemente, o reencontro com o seu marido, vendido em Campinas. Para tal, invertia a lógica senhorial, demonstrando a seu senhor, padre, que a separação era contrária aos preceitos religiosos. Em carta, atribuía-lhe a responsabilidade em compartilhar as buscas, argumentando que "Deus não quer que se aparte Conga de negro de Angola". Por outro lado, em andanças pelas ruas da cidade, buscando água nos chafarizes, seu olhar atento procurava entre os demais parceiros, aqueles que poderiam ajudá-la. Encontrou no escravo Claro, pedreiro alfabetizado, um elo impor-

Baltimore e Londres, The Johns' Hopkins University Press, 1974. Segundo o autor, a amplitude de tais atividades configura "uma clara instância na qual as contradições internas do sistema de plantation tornaram possível o desenvolvimento de padrões adaptativos elaborados pelos próprios escravos, padrões estes que contribuiram, de um lado, para o efetivo funcionamento do regime e, do outro, para a sua progressiva fraqueza" (pp. 209/10). forria".

(29) - ALGRANTI, Leila. Op. it., especialmente capítulo "A difícil al-

(30) - P. 1492 de 1868 a 1872. 
tante: um indivíduo que, manipulando os códigos do mundo branco, poderia viabilizar os meios, por ela concebidos, de atingir sua alforria.

A escravidão urbana condicionou os cativos a experiência e ajustamentos individualizados. Ao contrário do que pode ser verificado nas zonas rurais, o trabalho na cidade de São Paulo não pressupunha ritmos coletivos, praticamente inexistiam plantéis numerosos pertencentes a um mesmo senhor e a própria concorrência no mercado de trabalho intermitente levava os escravos a canalizar esforços e lutas a direções pessoais. Porém, transitavam livremente pelas ruas, mantinham pontos de encontro e de lazer noturnos, congregavam-se em festas das irmandades religiosas de homens pretos. Tais espaços transformavam-se em trocas sociais intensas, relações de amizade e afetivas que se estruturavam a partir da própria rotina de trabalho e que se estendiam para além dela. Organizava-se, portanto, no contexto citadino um intenso relacionamento integrupos negros, marcado por tensões, disputas de valentia, mas também por laços informais de solidariedade. Para o conjunto do grupo escravo formava-se em decorrência uma hierarquia interna marcante, fundamentada a partir das condições dadas pela escravidão e que se mostravam essenciais para o enfrentamento das vicissitudes a que estavam sujeitos.

A escravidão, enquanto regime extremamente opressivo, impôs aos escravos uma reorganização dos laços comunitários dos valores que regiam seus relacionamentos e solidariedades, e uma improvisação contínua do sobreviver, mediante arranjos multivariados. Ao contrário das imagens correntes, os autos criminais, recuperando memórias de escravizados, revelam homens e mulheres que protagonizaram suas próprias lutas e anseios, que os conduziram arduamente contra as imposições do regime. Sobrevivendo, isto é, resistindo, forjaram os aprendizados da liberdade. 